\title{
Letters
}

\section{Dysphasia during sleep due to an unusual vascular lesion}

SIR,-A recently studied patient gave an account that seemed to demonstrate that the content of a dream was affected by the presence of dysphasia developing during sleep.

A 37-year-old word processor salesman described a nightmare in which he was seated at the keyboard of an enormous word processor screen. To his distress he could not get the screen to show any words, only carriage return symbols. He woke at this point to feel that he could not move his right arm normally. Thinking he had merely not fully woken, he attempted to lean on his right elbow to get out of bed, and fell on the floor as the arm gave way. His wife was woken by his fall, but he found himself unable to tell her that he was alright. Heaviness of the arm lasted a few hours. His difficulty expressing himself began to improve in 1.5 hours but he was aware of hesitancy even 36 hours later, and for 2 weeks made errors at the typewriter. At first these were in either hand and sounded dysgraphic in nature, later only in the right hand which may still have been clumsy. Carotid angiography revealed a dissection of the left middle cerebral artery just proximal to its trifurcation and this is assumed to have been the cause of the patients ischaemic lesion. (figure). There was no evidence of fibromuscular dysplasia, and the patient did not show the features of Marfan's syndrome.

Patients often wake with established neurological deficit due to cerebral infarction, ${ }^{1}$ but this patient is unusual in describing a dysphasic difficulty during a dream just prior to waking. It is impossible of course to say whether the ischaemic event began before or during REM sleep though cerebral blood flow is lower in non REM sleep. The idea that focal cortical lesions can affect the content of dreams is of interest but does not seem to have been pursued by any systematic enquiry.

\section{Reference}

1 Marshall J. Diurnal variation in occurrence of strokes. Stroke 1977; 8: $230-1$.

The Middlesex Hospital,

MJG HARRISON

Mortimer Street,

London W1, UK
Figure $A P$ view of left carotid arteriogram showing aneurysmal dissection of middle cerebral artery. 